Article

\title{
Impact of Casing Eccentricity on Cement Sheath
}

\author{
Kui Liu ${ }^{1}$, Deli Gao ${ }^{1, *}$ and Arash Dahi Taleghani ${ }^{2}$ \\ 1 College of Petroleum Engineering, China University of Petroleum (Beijing), Beijing 102200, China; \\ 2015312009@student.cup.edu.cn \\ 2 Department of Energy and Mineral Engineering, Pennsylvania State University, University Park, PA 16802, \\ USA; aud440@psu.edu \\ * Correspondence: gaodeli@cup.edu.cn; Tel.: +86-010-8973-3281
}

Received: 2 August 2018; Accepted: 3 September 2018; Published: 25 September 2018

check for updates

\begin{abstract}
Sustained casing pressure (SCP) in shale gas wells caused by cement sheath failure can have serious impacts on safe and efficient gas production. Considering the fact that horizontal wells are widely used for production from shale, the cementing quality and casing centricity is barely ensured in these wells. Among other indications, the casing eccentricity is identified very often in wells with SCP problems in the Sichuan field in China. Hence, the objective of this study is to analyze the effect of the casing eccentricity on the integrity of the cement sheath. To better understand stress distribution in eccentric cement sheaths, an analytical model is proposed in this paper. By comparing the results of this model with the one's with centric casing, the impacts of the casing eccentricity on the integrity of the cement sheath is analyzed. During fracturing treatments, the casing eccentricity has a little effect on stress distribution in the cement sheath if the well is well cemented and bonded to the formation rock. However, on the contrary, the casing eccentricity may have serious effects on stress distribution if the cementing is done poorly. The debonding of casing-cement-formation interfaces can significantly increase the circumferential stress in the cement sheath. At the thin side of the cement sheath, the circumferential stress could be 2.5 times higher than the thick side. The offset magnitude of the casing eccentricity has little effect on the radial stress in the cement sheath but it can significantly increase the shear stress. We found that the risk of cement failure may be reduced by making the casing string more centralized, or increasing the thickness of the casing. The results provide insights for design practices which may lead to better integrity in shale gas wells.
\end{abstract}

Keywords: shale gas well; well integrity; hydraulic fracturing; casing eccentricity; cement sheath

\section{Introduction}

The development of multistage hydraulic fracturing and horizontal drilling has made the economic exploitation of shale oil and shale gas from low permeability shale formations possible. Shale gas production first became commercial in the United States and is now about to develop around the world. However, a reliable cementing job is necessary to prevent potential environmental impacts due to production and stimulation of these wells. The presence of high sustained annulus pressure in shale gas wells has created some operational and safety challenges for operators, especially when fracturing treatments are implemented through casing rather than tubing. Hence, more attention is required to address integrity concerns in horizontal wells, especially when the fluid pressure inside the casing is considerably high.

The analysis of the mechanical response of the cement sheath shows that the integrity of the cement sheath is affected by the mechanical properties of the cement, geometrical parameters and the mechanical properties of the formation rock [1]. The cement shrinkage can lead to circumferential fractures which can be propagated by the accumulation of gas with high pressure [2]. Finite Element Analysis (FEA) is widely used to simulate the emergence and propagation of fractures along the 
wellbore axial and circumferential directions [3-5]. Chu et al. analyzed the cement failure or formation of micro-annulus cracks caused by changes in fluid pressure and temperature [6]. Casing expansion caused by high internal pressure may also lead to radial cracks in the cement sheath $[7,8]$ or debonding [9]. During hydraulic fracturing in shale gas wells, incomplete or poor cementing can cause shear failure and broaching, especially along vertical sections of the wellbore $[10,11]$. These works are based on assuming that the casing is centered in the borehole; however, it is quite challenging to make sure that casing is completely centered in the well, particularly in horizontal wells [12].

Since casing strings are usually eccentric in wells, a thorough analysis is required to identify the susceptibility of the cement sheath to failure. Andrade et al. (2014) performed an experimental study on how, where and when temperature variations affecting the isolation capability of the cement sheath in cases with casing eccentricity [13]. Then, they used the FEA to evaluate the effect of casing stand-off and possible initial defects on stress and integrity of cement sheaths [14]. However, to date, there is no specific study to look at the stress of a cement sheath when the casing is eccentric in the well. In this paper, an analytical model based on the bipolar coordinate system is established to study the stress in a cement sheath with casing eccentricity. Furthermore, by considering high fluid pressure fluctuations during hydraulic fracturing treatments, the effect of casing inner pressure, the casing eccentricity, and the properties of casing and cement on the isolation capability of cement sheath is analyzed.

\section{Field Observations}

\subsection{Sustained Casing Pressure in Shale Gas Wells}

Natural gas may often migrate to the surface through the annulus or the channels among the cement sheath. Especially in the horizontal shale gas wells which are gone through hydraulic fracturing, most of the wells show sustained casing pressure (SCP) to some degrees. Based on the field data from shale gas wells in China, the change in the number of the wells with sustained annulus pressure during the whole life of the shale gas wells are shown in Figure 1a [15]. It can be seen that the percentage of wells with SCP has significantly increased from $19.04 \%$ before hydraulic fracturing to $63.70 \%$ after the hydraulic fracturing treatment. While $19.14 \%$ of wells show SCP after one month, $5.07 \%$ more wells show SCP after two months. The pressure in the annulus of shale gas wells in this area are also measured, and the results are shown in Figure 1b [15].

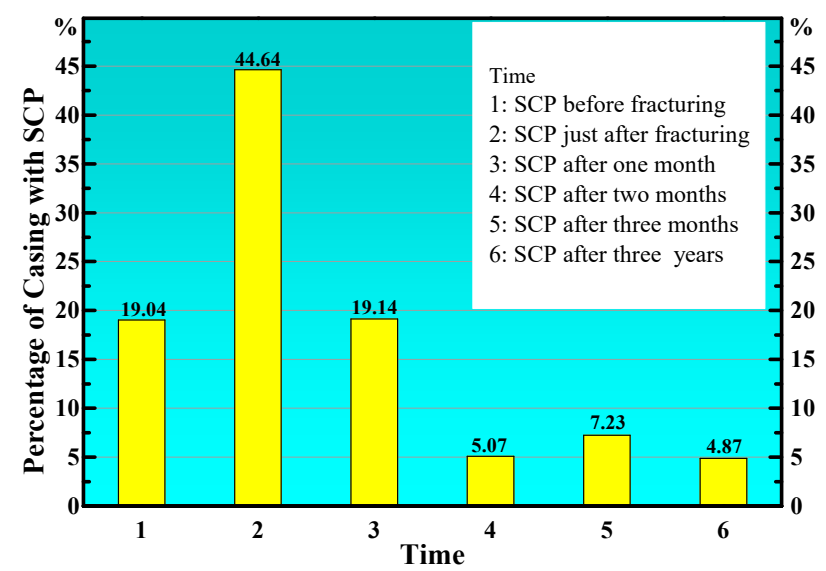

(a)

Figure 1. Cont. 


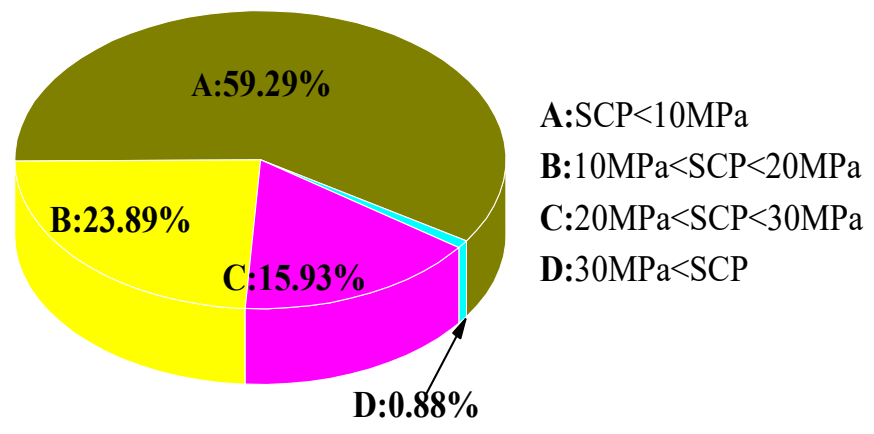

(b)

Figure 1. The sustained casing pressure in shale gas wells: (a) the percentage of wells with SCP during the whole life time of wells; (b) the percentage of the different SCP in wells.

\subsection{Casing Eccentricity in Shale Gas Wells}

The isolation scanner (Schlumberger technology) is used in the shale gas wells of this study to evaluate the wellbore integrity. The results show that casing eccentricity occurs very often in these wells, as shown in Figure 2, where the red dashed line indicates the center axis of the well and the black dashed line represents the center axis of the casing. It is extremely hard to make sure that the casing is laid absolutely centered in the field. From Figure 2, we can see that most of the length of the casing is eccentric in this well, which leads to eccentricity of the cement sheath. As the result, the thickness of the cement sheath varies along its circumference at different cross-sections. In Part 1 , the magnitude of the casing eccentricity is small so it can be treated as located at the center of the well, while in Part 2 and Part 3, the casing eccentricity increases significantly. The stress in the cement sheath may be affected by the casing eccentricity, and we try to understand the effect of the casing eccentricity on the stress distribution in the cement sheath to come with a solution to decrease SCP in similar wells in future.

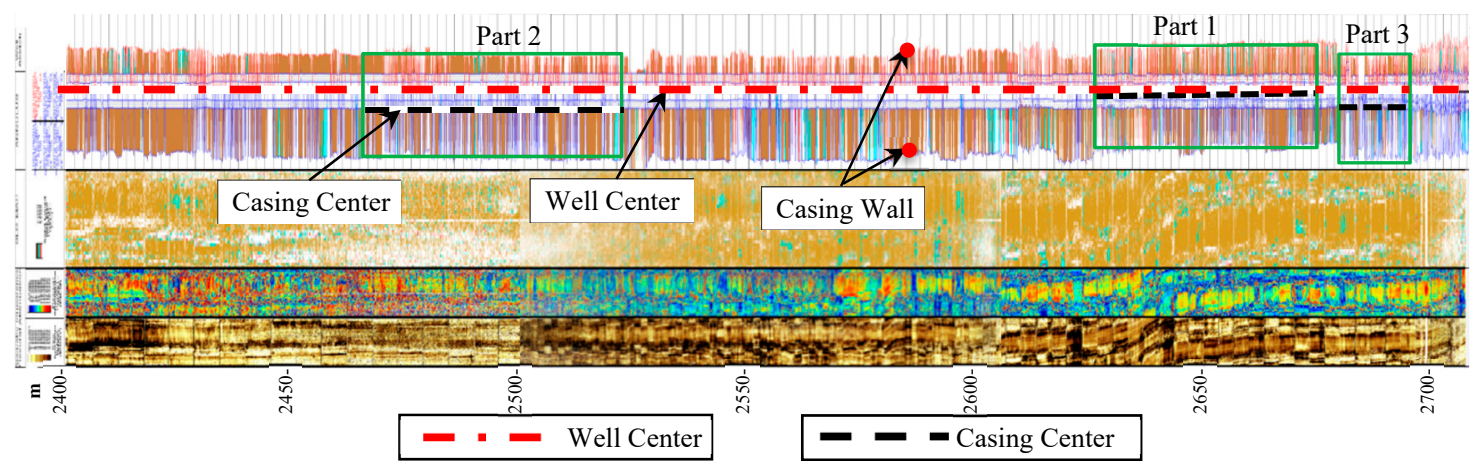

Figure 2. Isolation Scanner measurements show the quality of cementing work along a horizontal section of a well.

\section{Mechanic Model}

Multi-stage hydraulic fracturing technology is widely used in shale gas wells, hence the casing-cement-formation system undergoes periodic changes of casing internal pressure (fluid pressure in casing) between $20 \mathrm{MPa}$ and $90 \mathrm{MPa}$ during fracturing treatments. Meanwhile, the casing-cement-formation system is also experiencing the crustal stress environment. As the axial length is much larger than the diameter of the wellbore, the mechanical model of the casing-cement-formation can be treated as a plane strain model.

There are two major factors which cause casing eccentricity in shale gas wells: (1) the difficulties in assuring that the well is drilled perfectly straight in the horizontal section; (2) the casing bending between two centralizers due to the gravity and the axial stress (Figure 3a). The sketches of loads acting 
on the casing-cement-formation system for centric and eccentric casings are shown in Figure $3 b$,c. For future reference, the casing-cement interface is named the first interface and the cement-formation interface is named the second interface. The crustal stress is $\sigma_{\mathrm{o}}$ and casing internal pressure is shown by $P_{\mathrm{i}}$.

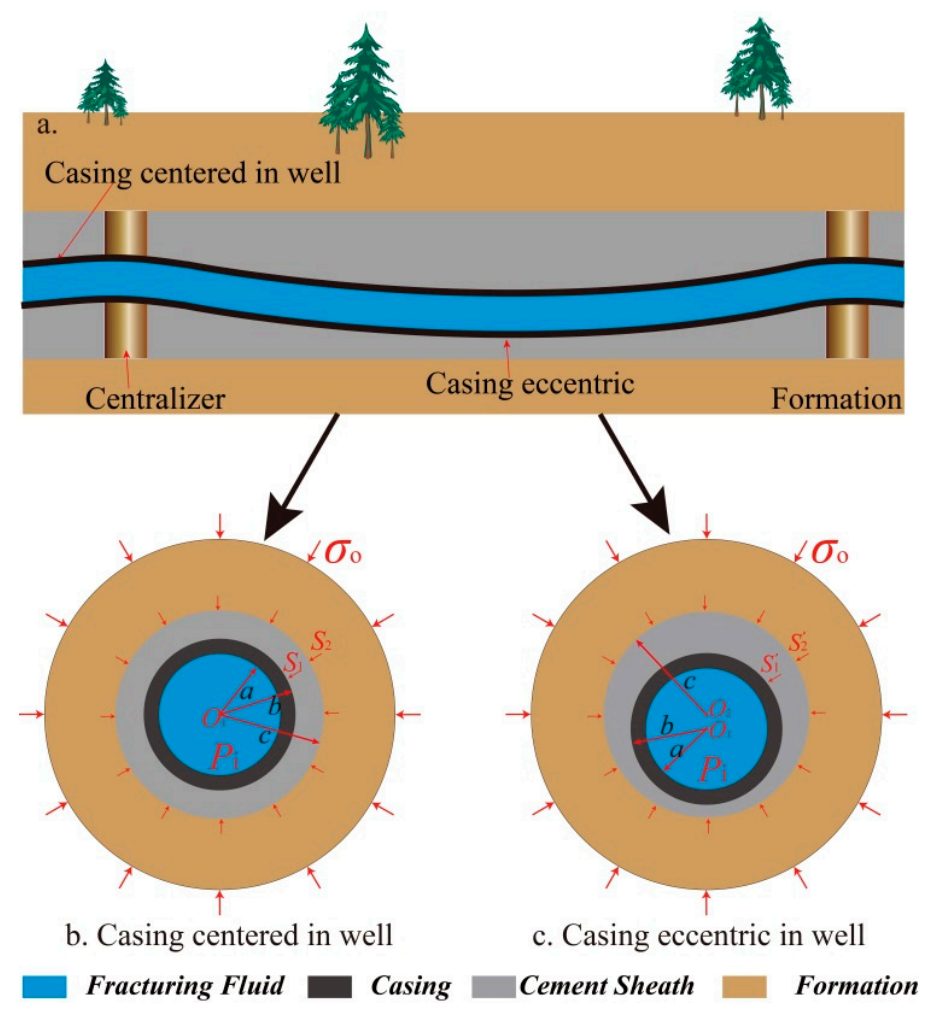

Figure 3. Sketch of a casing-cement-formation system in a horizontal well.

\subsection{Stress on Interfaces}

As shown in Figure $3 b$, the casing is centric and the casing-cement-formation system consists of three rings, including the casing string, cement sheath and formation rock. The thickness of the cement sheath is uniform around the casing. The boundary conditions at the interface are stress and displacement continuities. The Lamé formula in elasticity can give the stress in each ring for the plane strain geometry. The polar coordinate system is used to simplify the expressions. By employing the Lamé formula [16], the radial stress on interfaces can be achieved according to the stress and displacement continuities at the interfaces, as shown in

$$
\left\{\begin{array}{l}
S_{1}=\frac{k_{11}^{c}\left(k_{21}^{t}+k_{22}^{s}\right) \cdot P_{1}+k_{12}^{t} k_{12}^{s} \cdot \sigma_{0}}{k_{21}^{c}+k_{22}^{t}\left(k_{21}^{t}+k_{22}^{s}\right)-k_{11}^{t} k_{12}^{t}} \\
S_{2}=\frac{k_{11}^{c}\left(k_{21}^{t}+k_{22}^{s}\right) \cdot P_{1}+k_{12}^{t} k_{12}^{s} \cdot \sigma_{0}}{k_{21}^{c}+k_{22}^{t}\left(k_{21}^{t}+k_{22}^{s}\right)-k_{11}^{t} k_{12}^{t}} \cdot \frac{k_{11}^{t}}{k_{21}^{t}+k_{22}^{s}}+\frac{k_{12}^{s} \cdot \sigma_{0}}{k_{21}^{t}+k_{22}^{s}}
\end{array}\right.
$$

The details of deriving these equations are shown in our previous paper [17]. The $k$ indices are used for simplification purposes [18].

\subsection{Stress in Cement Sheath}

As shown in Figure 3c, the casing eccentricity causes uneven thickness of the cement sheath. The radial stress $S_{1}^{\prime}$ on the first interface and $S_{2}^{\prime}$ on the second interface which are induced by the crustal stress and casing internal pressure are the external loads. The stress in the cement sheath with casing eccentricity can be much different from the stress in wells with no casing eccentricity. The conventional polar coordinate system is very useful to calculate the stress of a cement sheath when casing is centered 
in wells, but it is not very useful for calculating stresses in the case of eccentricity. Therefore, the bipolar coordinate system [19] is employed for stress analysis here. As the casing-cement-formation system has reached the equilibrium state after cement is set, the following hypotheses are assumed to simplify stress analysis:

- Tectonic stresses are assumed to be isotropic;

- As we focus on analyzing the effect of eccentricity on the stress of the cement sheath, the external loads on the surfaces of the cement sheath are treated to be equal to the stress calculated according to Equation (1);

- The cementing job is well done and no discontinuity exists in the cement sheath;

Since uniform tectonic stress is only considered in the model, the analytical model derived in this paper can only be used in a field with uniform crustal stress. The stress of the cement sheath caused by casing eccentricity in non-uniform tectonic stress is much more complex and needs to be studied in future.

\subsubsection{Mechanistic Model of an Eccentric Cement Sheath}

As shown in Figure 4, the eccentric cement sheath with double centers is simplified as an eccentric annulus and the bipolar coordinate system is employed to show the geometry parameters. The bipolar coordinate system is an orthogonal curvilinear coordinate system and the $C_{1}=\lambda i$ and $C_{2}=-\lambda i$ are the two focus points, corresponding to the points $(0, \lambda)$ and $(0,-\lambda)$ on the plane defined by the Cartesian coordinate system. $\lambda$ is a positive real number. The point $M$ is an arbitrary point shown in the bipolar coordinate system. $\alpha$ and $\beta$ are coordinate axes of the bipolar coordinate system [20]. The conversion of coordinates from the bipolar coordinate system to the Cartesian coordinate system is as follows:

$$
\left\{\begin{array}{l}
x=\lambda \cdot \sin \beta /(\cosh \alpha-\cos \beta) \\
y=\lambda \cdot \sinh \alpha /(\cosh \alpha-\cos \beta)
\end{array}\right.
$$

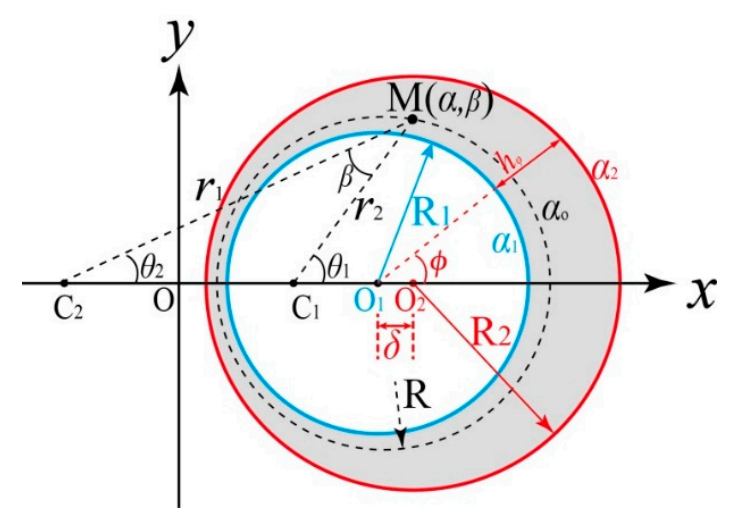

Figure 4. Bipolar coordinate system for stress analysis in a cement sheath.

In Figure $4, \alpha=\alpha_{1}$ and $\alpha=\alpha_{2}$ are the inner and outer interfaces of the cement sheath, respectively. $\mathrm{O}_{1}$ is the center of the inner circle $\alpha_{1}$, with the radius $r_{1} ; \mathrm{O}_{2}$ is the center of the outer circle $\alpha_{2}$, with the radius $r_{2}$; and $\delta$ is the distance between $\mathrm{O}_{1}$ and $\mathrm{O}_{2}$. The values of $\alpha_{1}, \alpha_{2}$ and $\lambda$ are calculated according to $r_{1}, r_{2}, \delta$, as described in Equation (A7). $\beta$ is the angle between $r_{1}$ and $r_{2}$. Using geometry, $\beta$ can be represented by $\lambda, r_{1}$ and $r_{2}$.

$$
\beta=\arccos \left(\frac{4 \lambda^{2}-r_{1}^{2}-r_{2}^{2}}{-2 r_{1} r_{2}}\right)
$$


where $r_{1}=\sqrt{\left(x_{\mathrm{o}}-\lambda\right)^{2}+R^{2}+2 R\left(x_{\mathrm{o}}-\lambda\right) \cos \phi_{\mathrm{o}}}, r_{2}=\sqrt{\left(x_{\mathrm{o}}+\lambda\right)^{2}+R^{2}+2 R\left(x_{\mathrm{o}}+\lambda\right) \cos \phi_{\mathrm{o}}}, x_{\mathrm{o}}$ is the center of the circle $\alpha_{0} ; R$ is the radius of this circle; and $\varphi_{\mathrm{o}}$ is the angle of point $\mathrm{M}$ with respect to axis $x$.

The derivation of the analytical equations for the stress at any point in the cross section of the cement sheath are presented in Equation (A11), Equation (A12) and Equation (A13) in Appendix A. On the inner interface of the cement sheath, $\alpha=\alpha_{1}$, the circumferential stress is shown in Equation (A9). On the outer interface of the cement, $\alpha=\alpha_{2}$, the circumferential stress is shown in Equation (A10).

\subsubsection{Model Accuracy Verification}

FEA is widely used to analyze the stress of the wellbore system. Here, we use a commercial FEA package, ABAQUS, to simulate the stress in a cement sheath. According to symmetry, half of the cement sheath is modeled here. The size of the inside diameter of the cement is $0.139 \mathrm{~m}$ and the outside diameter is $0.189 \mathrm{~m}$. The distance of the casing center from the borehole center is $0.01 \mathrm{~m}$ (eccentricity). The elastic modulus of the cement sheath is $25 \mathrm{GPa}$ and the Poisson's ratio is 0.3 . The pressure at the inner interface of the cement sheath is set as $30 \mathrm{MPa}$ and the pressure at the outer interface of the cement sheath is set as $50 \mathrm{MPa}$. The simulated results are shown in Figure 5a. The values of circumferential stress at different points on the inner interface of the cement sheath are shown in Figure $5 \mathrm{~b}$ (black line). Using the same parameters, the circumferential stress at the inner interface of the cement sheath calculated by the analytic method is shown in Figure $5 b$ (red line). In Figure 5b, the angle $\varphi=0^{\circ}$ means that the considered point is located at the thickest part of cement sheath and $\varphi=180^{\circ}$ means that the calculated point is located at the thinnest part of cement sheath. The difference between the analytical calculation and ABAQUS simulation are also shown in Figure 5b.

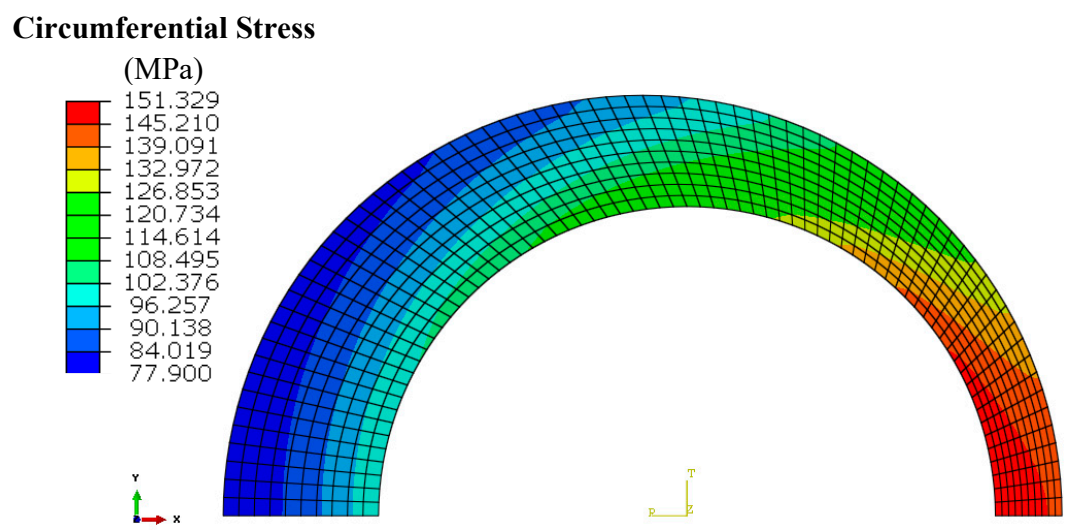

(a)

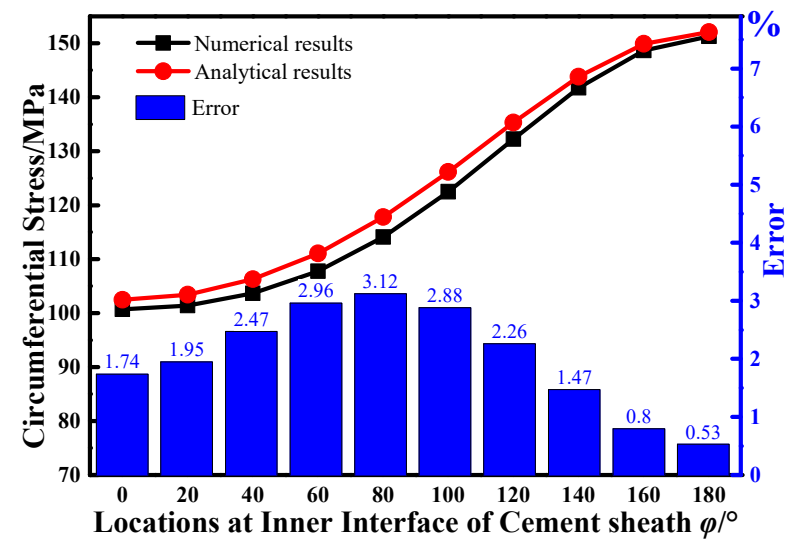

(b)

Figure 5. (a) FEA results for the circumferential stress on the inner interface of the cement sheath; (b) comparisons between ABAQUS numerical results and analytical results. 
Figure 5 shows that the largest circumferential stress is $152 \mathrm{MPa}$ and is located at the thinnest part of the inner interface of the cement sheath. Meanwhile, the circumferential stress increases with the decrease of the thickness of the cement sheath and the circumferential stress at the thickest part of cement sheath is $102 \mathrm{MPa}$. From the error analysis between the results calculated by FEA and analytical method, the smallest error is $0.53 \%$ at $\varphi$ equal to $180^{\circ}$ and the largest error is $3.12 \%$ when the angle $\varphi$ is $80^{\circ}$. The analytical method proposed in this paper is shown to be reasonable for calculating stress distribution in an eccentric cement sheath.

There exist different yield criteria for assessing the yield failure of the rock and cement. The advantage of the Drucker-Prager yield criterion is that not only the intermediate principal stress is considered but also the average stress is considered. The Drucker-Prager yield criterion used in this study is similar to our previous work [21].

\section{Stress in an Eccentric Cement Sheath}

The boundary conditions of the radial stresses $S_{1}^{\prime}$ and $S_{2}^{\prime}$ on the inner and outer interface of cement sheath can be achieved by substituting the $P_{\mathrm{i}}$ (casing internal pressure) and $\sigma_{\mathrm{o}}$ (crustal stress) into Equation (1). The stress of the cement sheath can be calculated according to Equation (A9) and Equation (A10). In this section, we focus on analyzing the stress in the cement sheath caused by the crustal stress and casing internal pressure.

In order to analyze the effect of casing internal pressure on the stress of the cement sheath, the crustal stress $\sigma_{\mathrm{o}}$ is set to zero and the range of $P_{\mathrm{i}}$ is set as increasing from $0 \mathrm{MPa}$ to $100 \mathrm{MPa}$. With the increase of casing internal pressure, the $S_{1}^{\prime}$ and $S_{2}^{\prime}$ on the cement-formation interface are shown in Figure 6. In contrast, the $P_{\mathrm{i}}$ is set as $0 \mathrm{MPa}$ and the $\sigma_{\mathrm{o}}$ is set as increasing from $0 \mathrm{MPa}$ to $100 \mathrm{MPa}$ to analyze the effect of crustal stress on the stress in the cement sheath. The variations of $S_{1}^{\prime}$ and $S_{2}^{\prime}$ with the change of crustal stress are shown in Figure 6. The model parameters are shown in Table 1 [22].

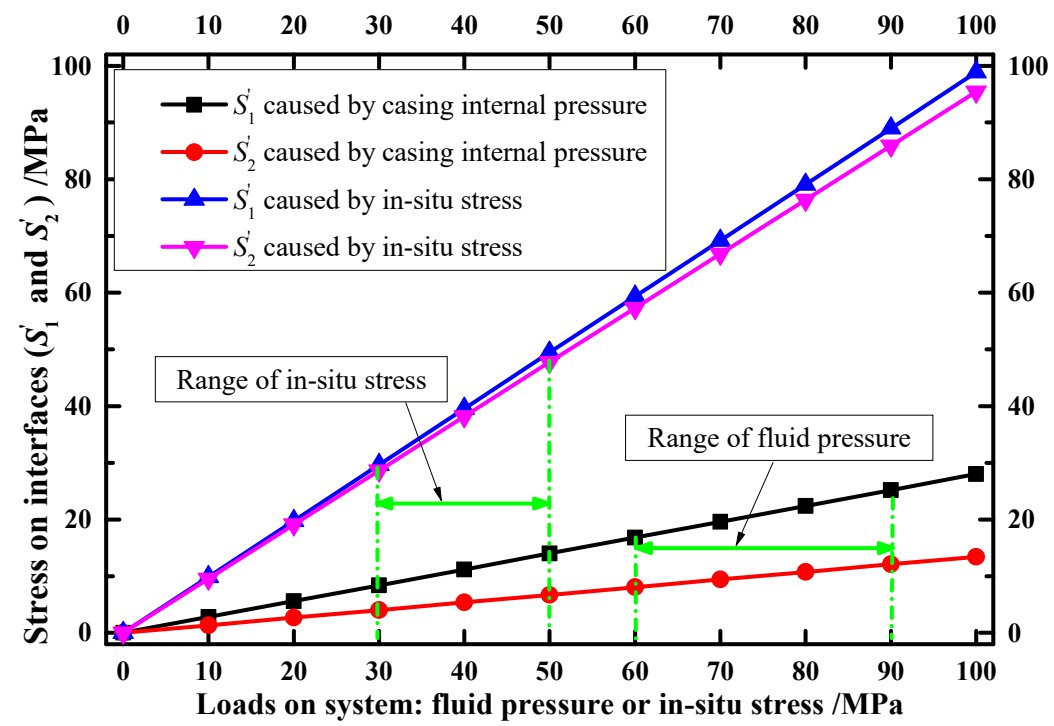

Figure 6. The variations of $S_{1}^{\prime}$ and $S_{2}^{\prime}$ with the change of crustal stress and casing internal pressure.

Table 1. Model parameters for casing, cement sheath and formation.

\begin{tabular}{ccccc}
\hline & Outer Diameter/m & Thickness/mm & Elastic Modulus/GPa & Poisson Ratio \\
\hline Casing & 0.1397 & 12.14 & 210 & 0.25 \\
Cement & 0.2223 & 41.28 & 20 & 0.3 \\
Formation & $\geq 10$ & $\geq 10$ & 25 & 0.3 \\
\hline
\end{tabular}

Figure 6 shows that the $S_{1}^{\prime}$ and $S_{2}^{\prime}$ are very similar to each other and $S_{1}^{\prime}$ is just a little larger than $S_{2}^{\prime}$. It means that the difference between $S_{1}^{\prime}$ and $S_{2}^{\prime}$ is small when the crustal stress is only considered, 
and we can also see that the stresses on the interfaces are close to the crustal stress. The $S_{1}^{\prime}$ and $S_{2}^{\prime}$ caused by the fluid pressure in the casing are much lower than that caused by the crustal stress. The difference between $S_{1}^{\prime}$ and $S_{2}^{\prime}$ caused by fluid pressure is larger and the effect of the larger stress difference on the stress of cement sheath is studied in the following. The in-situ stress in this area is ranging from $30 \mathrm{MPa}$ to $50 \mathrm{MPa}$ according to reported leak off tests, and the casing internal pressure is varying between $60 \mathrm{MPa}$ and $90 \mathrm{MPa}$ according to the recordings.

\subsection{Contribution of Crustal Loads}

The crustal stress on the outer face of the casing-cement-formation is considered in this section to analyze the stress in the cement sheath when casing exhibits eccentricity in the well.

\subsubsection{Variation of Circumferential Stress with Radius}

Most of the shale gas formations in China are located at the depth of $3000-5000 \mathrm{~m}$. Thus, the crustal stress $\sigma_{\mathrm{o}}$ is set as $40 \mathrm{MPa}$. Meanwhile, as the fluid pressure on the inner face of casing is not considered here, the $P_{\mathrm{i}}$ in the casing is set as $0 \mathrm{MPa}$. According to Equation (1) and Figure $6, S_{1}^{\prime}$ on the first interface is $49.44 \mathrm{MPa}$ and $S_{2}^{\prime}$ on the second interface is $47.73 \mathrm{MPa}$. The parameters of the casing, cement and formation are shown in Table 1.

As shown in Figure 4, the positive direction of the $x$-axis is set as the start line and $\varphi$ is the angle between the $x$-axis and the location vector of point $\mathrm{M}$. When the angle $\varphi$ is smaller than $180^{\circ}$, the thickness of the cement, $h_{\varphi}$, decreases with the increase of $\varphi$. The stress in the cement sheath along circles with different radii is calculated using Equation (A9) as shown in Figure 7, where the thickness of the cement sheath $h_{\varphi}$ is divided into four parts: $R_{1}$ is the inside radius of cement sheath and $R=R_{1}+B h_{\varphi}(B=0.25,0.5,0.75,1)$ is the radius of the circle where the circumferential stress of point $\mathrm{M}$ is calculated. The eccentricity $\delta$ (also the distance of the casing center from the borehole center, see Figure 4) is $0.025 \mathrm{~m}$ and, the thickness of cement sheath is ranging from $0.0163 \mathrm{~m}$ to $0.0663 \mathrm{~m}$. Figure 7 shows circumferential compressive stress in the cement sheath by only considering the crustal stress. In accordance with the previous study about the stress in the cement sheath with no eccentricity [1], the largest circumferential stress is at the inner interface of the cement sheath and with the increase of the distance from the casing, the circumferential stress decreases. Meanwhile, the circumferential stress decreases with the increase of angle $\varphi$, and then the stress increases after the $\varphi$ is larger than $180^{\circ}$. This means that when the crustal stress is only applied on casing-cement-formation system, the largest stress is located at the thickest part of the cement sheath. The maximum circumferential stress is $46.7 \mathrm{MPa}$ and the lowest circumferential stress is $37.6 \mathrm{MPa}$. The circumferential stress at the inner interface of the cement calculated according to Equation (1) is 45.5 MPa when the thickness of the cement is uniform (no eccentricity).

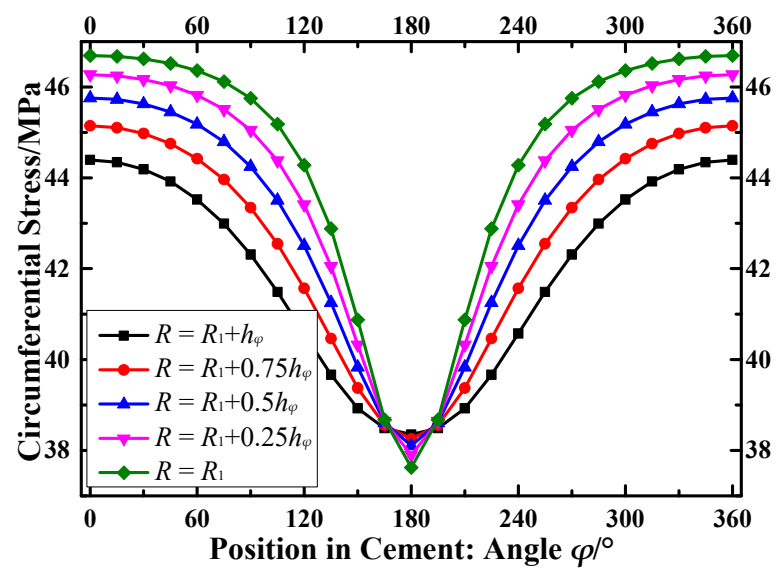

Figure 7. Variation of the circumferential stress with the azimuth angle $\varphi$ at different radii $R$. 


\subsubsection{Variation of Circumferential Stress with Eccentricity}

In this section we investigate the impact of eccentricity magnitude on stress distribution in the cement sheath. Only the crustal stress is considered here. The variation in the circumferential stress of the cement sheath with different eccentricity magnitudes: $0 \mathrm{~m}, 0.005 \mathrm{~m}, 0.015 \mathrm{~m}, 0.025 \mathrm{~m}$ and $0.035 \mathrm{~m}$ are shown in Figure 8. The parameters are the same as Table 1.

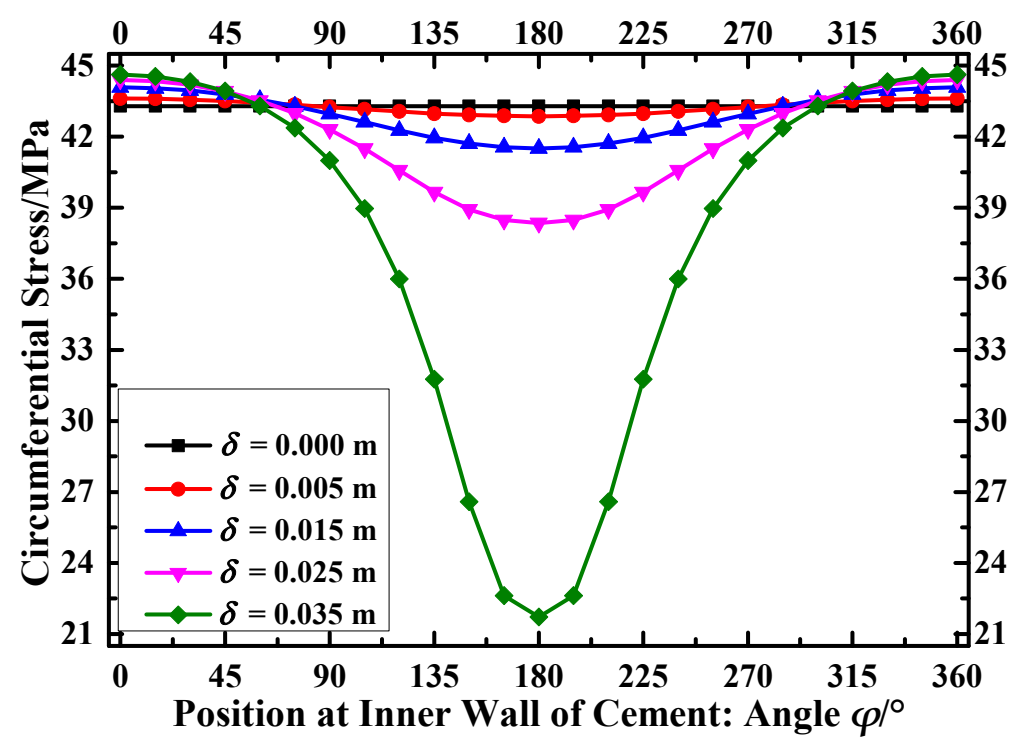

Figure 8. Variation of circumferential stress with azimuth angle $\varphi$ for different eccentricity magnitudes.

Figure 8 shows that, at the thickest part of cement sheath, where the angle $\varphi$ is smaller than $50^{\circ}$ or larger than $310^{\circ}$, the eccentricity $\delta$ has little effect on the circumferential stress in the cement sheath. The circumferential stress decreases non-linearly with the decrease of the cement thickness. In case of low eccentricity i.e., $\delta$ varies between $0 \mathrm{~m}$ and $0.005 \mathrm{~m}$, the stress almost remains constant. In larger eccentricities, the stress decreases quickly. At the thin side of the cement sheath, when the azimuth angle $\varphi$ is changing between $160^{\circ}$ and $200^{\circ}$, the stress changes rapidly with the increase of eccentricity. We can see in the plot that when the eccentricity is $0.035 \mathrm{~m}$, the lowest circumferential stress is $21.7 \mathrm{MPa}$, which is much lower than the stress of the cement sheath with no eccentricity.

\subsubsection{Equivalent Stress}

Failure in the cement sheaths are often assessed with Drucker-Prager model. To have a precise evaluation of the healthiness of the cement sheath, the previous results can also be recalculated based on Drucker-Prager equivalent stress. The equivalent stresses in the thin side of the cement sheath are shown in Figure 9, where eccentricity is assumed to be $0 \mathrm{~m}, 0.005 \mathrm{~m}, 0.015 \mathrm{~m}, 0.025 \mathrm{~m}$ and $0.035 \mathrm{~m}$, respectively. The change of eccentricity has little effect on the equivalent stress at the thin side of the cement sheath. With the increase of eccentricity, the equivalent stress decreases slowly. The failure of the cement sheath is not mainly caused by the crustal stress, because it is much lower than the limit value $k$. 


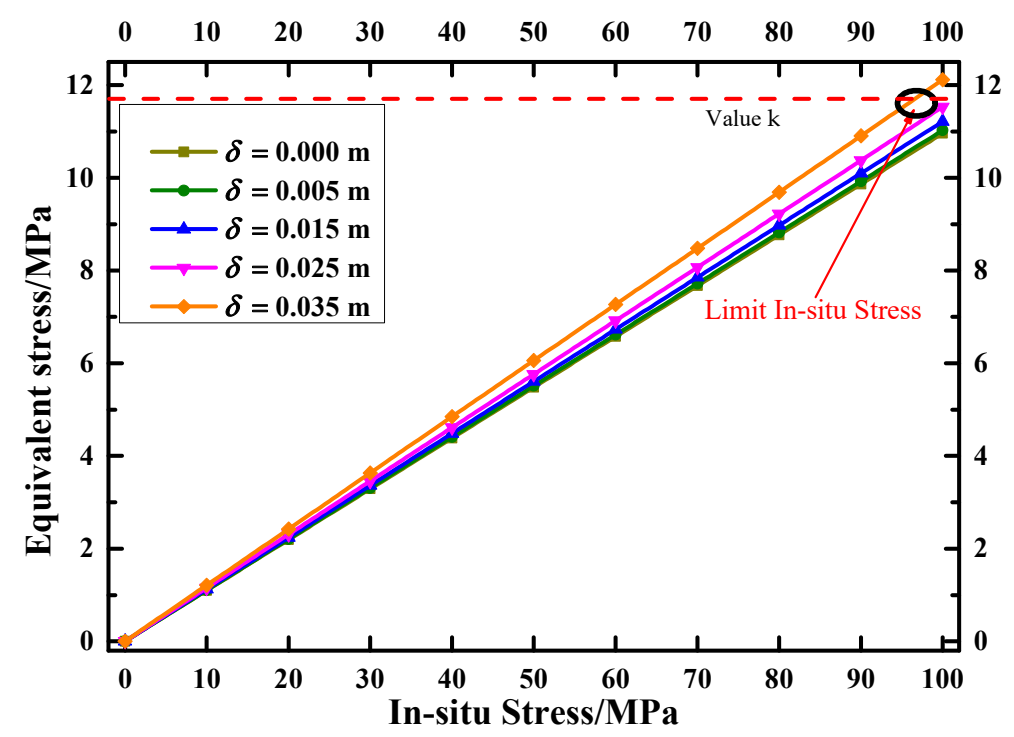

Figure 9. Variation of equivalent stress with the increase of crustal stress in different eccentricity $\delta$.

\subsection{Contribution of Fluid Pressure}

\subsubsection{Variation of Circumferential Stress with Radius}

Hydraulic fracturing treatments and other operations can increase fluid pressure inside the casing, the interface of the casing is pushed outwards to the cement sheath by the casing internal pressure and causes stress changes on the inner and outer interface of the cement sheath. In this section, the effect of the fluid pressure is only considered. The fluid pressure is assumed to be $50 \mathrm{MPa}$ and no crustal stress. The stress $S_{1}^{\prime}$ on the first interface is $14.0 \mathrm{MPa}$ and $S_{2}^{\prime}$ on the second interface is $6.7 \mathrm{MPa}$ according to Equation (1) using parameters of Table 1.

Here, we focus on four points along the thickness of the cement sheath $h_{\varphi} . R_{1}$ is the inside radius of the cement sheath and $R=R_{1}+B h_{\varphi}(B=0.25,0.5,0.75,1)$ is the radius of the circle in the cement sheath where the circumferential stress is calculated. The eccentricity is $0.025 \mathrm{~m}$ and the cement thickness is ranging from $0.0163 \mathrm{~m}$ to $0.0663 \mathrm{~m}$.

Figure 10 shows that the circumferential tensile stress is lower in larger distances. Meanwhile, the tensile stress in cement sheath increases with the increase of the cement thickness. The stress distribution for this case is different from the results of the stress caused by crustal stress. However, the tensile stress on the outer interface is larger than on the inner interface at the thickest side of cement sheath. The largest tensile stress is mostly on the inner interface of the cement sheath but around the thinnest part, the largest tensile stress is on the outer interface. The maximum tensile stress is $36.3 \mathrm{MPa}$. Compared with the tensile stress $17.0 \mathrm{MPa}$ in the cement sheath with no eccentricity, the casing eccentricity significantly increases the tensile stress in the cement sheath. 


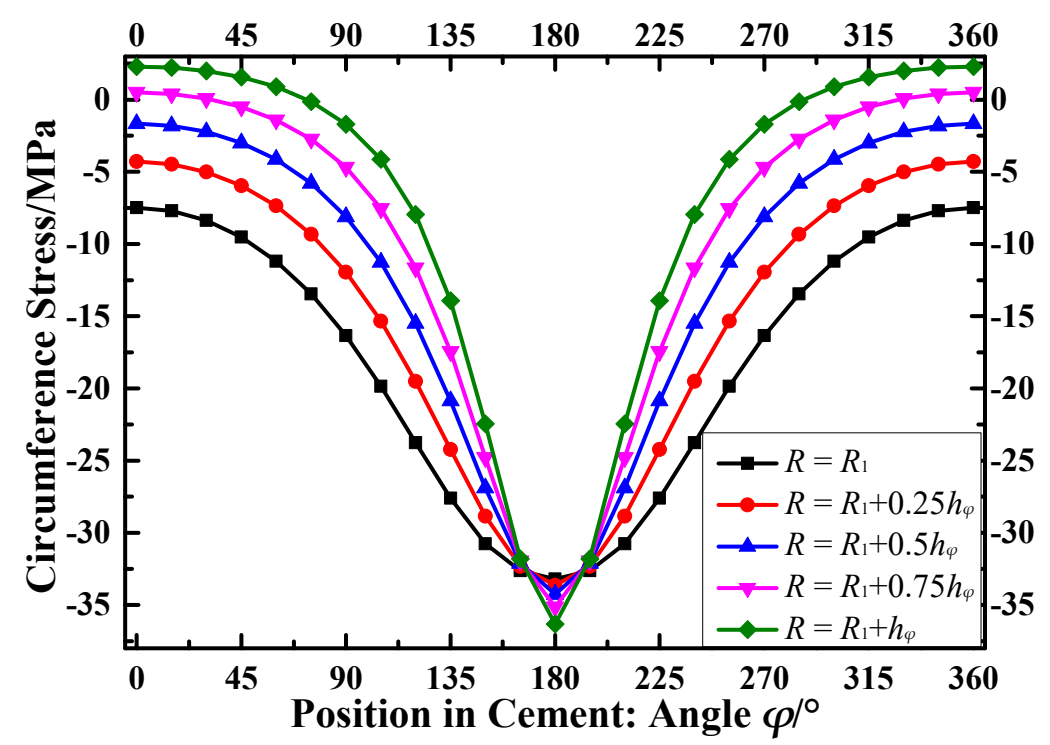

Figure 10. Variation of the circumferential stress in the cement sheath with the increase of azimuth angle $\varphi$ at radius $R$.

\subsubsection{Variation of Circumferential Stress with Eccentricity}

Considering fluid pressure inside the casing, the effect of eccentricity, $\delta$, on the stress in the cement sheath can be analyzed. At different eccentricity, the stress can be calculated according to Equation (A14) and the variations of circumferential stress are shown in Figure 11, where eccentricity is $0 \mathrm{~m}, 0.005 \mathrm{~m}, 0.015 \mathrm{~m}, 0.025 \mathrm{~m}$ and $0.035 \mathrm{~m}$.

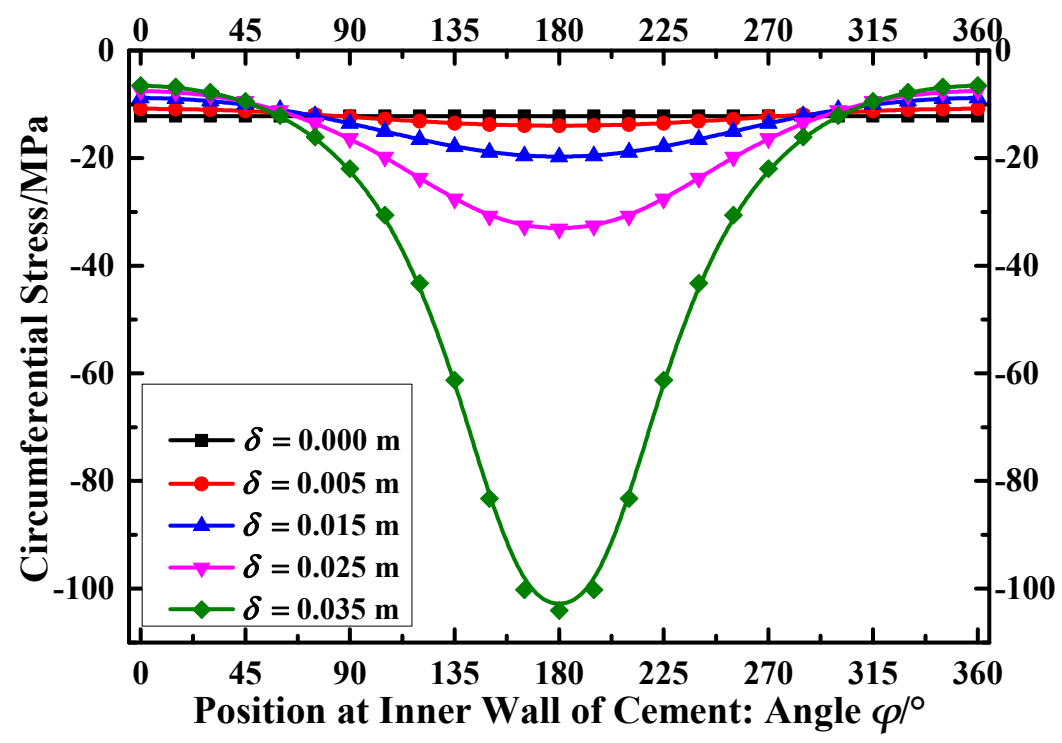

Figure 11. Variation of circumferential stress with azimuth angle $\varphi$ for different eccentricities.

Figure 11 shows that variations of circumferential stress with azimuth angle $\varphi$ caused by fluid pressure is opposite to the variation of stress caused by crustal stress. The circumferential stress of the cement sheath does not increase linearly with the increase of eccentricity. Around the thinnest part, where the angle $\varphi$ is smaller than $60^{\circ}$ or larger than $300^{\circ}$, the change of eccentricity has little effect on the circumferential stress. If the eccentricity is varying from $0 \mathrm{~m}$ to $0.005 \mathrm{~m}$, the stress almost remains constant. In larger eccentricities, the stress increases quickly. Most importantly, in the thick side, $\varphi$ is between $160^{\circ}$ and $200^{\circ}$, the stress increases rapidly with the increase of eccentricity. Based on 
the plot when the eccentricity is reaching $0.035 \mathrm{~m}$ in this example, the maximum circumferential stress is $125.7 \mathrm{MPa}$ at the thickest point, which is much larger than the stress with no eccentricity.

\subsubsection{Equivalent Stress}

The variation of wellbore pressure may also change stress in the cement sheath. Considering the subsequent change of three principle stresses (circumferential tress, radial stress and axial stress) in the cement sheath, the equivalent stress at the thinnest section of the cement sheath are shown in Figure 12, where eccentricity is assumed to be $0 \mathrm{~m}, 0.005 \mathrm{~m}, 0.015 \mathrm{~m}, 0.025 \mathrm{~m}$ and $0.035 \mathrm{~m}$.

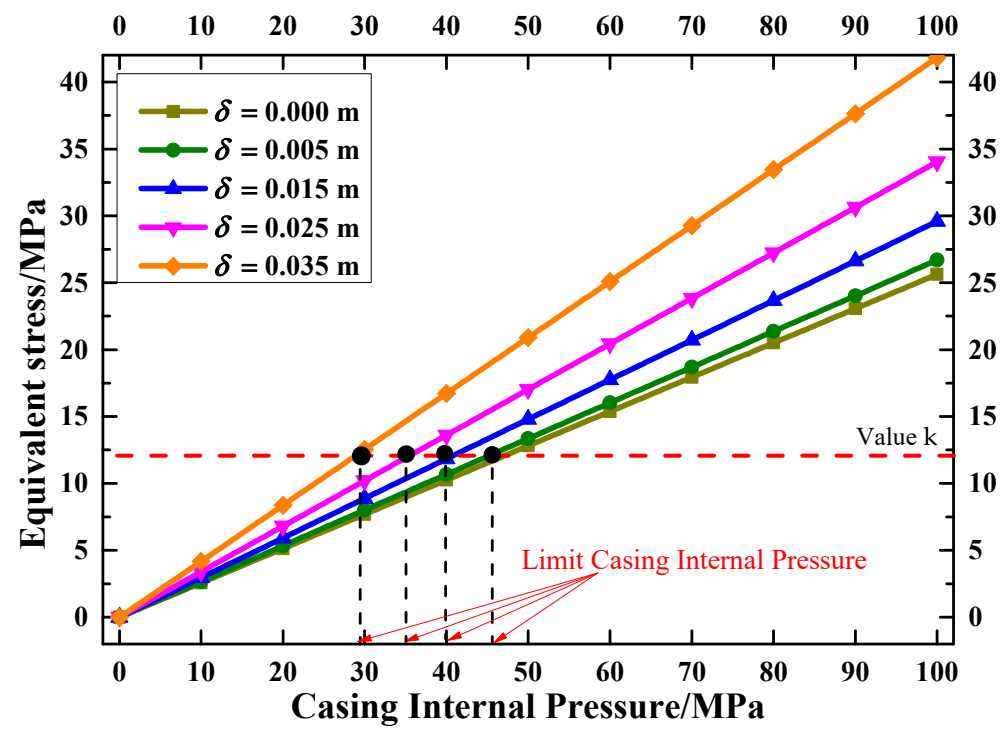

Figure 12. Variation of equivalent stress with the increase of casing internal pressure in different eccentricities, $\delta$.

Figure 12 shows that eccentricity may seriously affect the equivalent Drucker-Prager stress of the cement sheath at the thin side. With the increase of fluid pressure, the equivalent stress increases faster at larger eccentricities. In good cementing jobs, with the casing eccentricity lower than $0.005 \mathrm{~m}$, the limiting wellbore pressure for the yield failure of the cement sheath is $45 \mathrm{MPa}$. When the eccentricity is larger than $0.025 \mathrm{~m}$, the limit fluid pressure to ensure the integrity of the cement sheath decreases to be lower than $40 \mathrm{MPa}$. In addition, the limit casing internal pressure for cement integrity is $35 \mathrm{MPa}$ and $29 \mathrm{MPa}$ when the casing eccentricity is $0.025 \mathrm{~m}$ and $0.035 \mathrm{~m}$, respectively.

\section{Sensitivity Analysis and Case Study}

As aligning the casing perfectly along the wellbore axis is hard to achieve, a good understanding of the effect of the casing eccentricity on the stress of the cement sheath is very meaningful for increasing the integrity of cement sheath. According to the above discussions, stress distribution in a cement sheath disturbed by the casing eccentricity shows that the largest stress is located at the thin side on the inner interface of the cement sheath. Here, in sensitivity analysis, the effects of the thickness of casing, the thickness and elastic modulus of the cement sheath, and eccentricity are analyzed.

\subsection{Casing Thickness}

The thickness of the casing string may affect casing resistance against collapse and debonding. We assume that casing thickness can range from $0.008 \mathrm{~m}$ to $0.02 \mathrm{~m}$, here. The inside diameter of the casing is set as $0.116 \mathrm{~m}$ and the average thickness of the cement sheath is set as $0.065 \mathrm{~m}$. The crustal stress is $35 \mathrm{MPa}$ and the wellbore pressure is $75 \mathrm{MPa}$. The eccentricity is assumed to be $0.00 \mathrm{~m}, 0.01 \mathrm{~m}$, $0.02 \mathrm{~m}, 0.03 \mathrm{~m}, 0.04 \mathrm{~m}$. Other parameters of the casing, cement and formation are shown in Table 2 . The variations of equivalent stress with the casing thickness are shown in Figure 13. 
Table 2. Parameters of the casing, cement and formation.

\begin{tabular}{ccccccc}
\hline & ID (m) & Thickness (m) & $\begin{array}{c}\text { Elastic } \\
\text { Modulus (GPa) }\end{array}$ & $\begin{array}{c}\text { Poisson } \\
\text { Ratio }\end{array}$ & $\begin{array}{c}\text { Compressive } \\
\text { Strength (MPa) }\end{array}$ & $\begin{array}{c}\mathbf{k} \\
(\mathbf{M P a})\end{array}$ \\
\hline Casing & $0.1-0.4$ & 0.012 & 210 & 0.25 & $\mathrm{~N} / \mathrm{A}$ & $\mathrm{N} / \mathrm{A}$ \\
Cement & $0.124-0.424$ & 0.065 & 15 & 0.3 & $67 \mathrm{MPa}$ & 9.5 \\
Formation & $0.254-0.554$ & $>10$ & 25 & 0.3 & $\mathrm{~N} / \mathrm{A}$ & $\mathrm{N} / \mathrm{A}$ \\
\hline
\end{tabular}

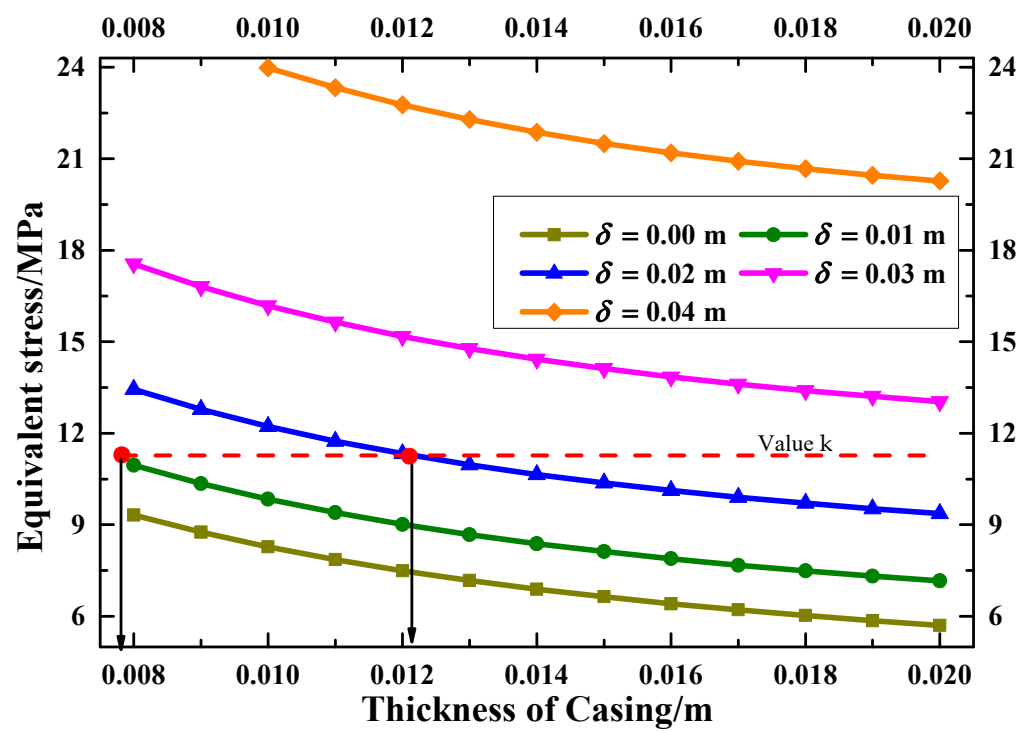

Figure 13. Variation of equivalent stress of the cement sheath with the increase of casing thickness.

Figure 13 shows that the larger casing thickness can decrease the stress in the cement sheath. However, in practice, thicker casing costs more. Thus, an optimal design is required. If eccentricity is larger than $0.03 \mathrm{~m}$, the stress in the cement sheath cannot be lowered than allowable value $\mathrm{k}$ for the case with limited casing thickness, which means the failure of the cement sheath during the hydraulic fracturing is unavoidable if the casing thickness is only adjusted. The casing strings used in shale gas fields in China are mostly thinner than $0.016 \mathrm{~m}$, the eccentricity should be smaller than $0.02 \mathrm{~m}$ to ensure the integrity of the cement sheath. Otherwise, increasing casing thickness becomes a meaningful solution.

\subsection{Thickness of the cement sheath}

Thickness of the cement sheath is mainly driven by casing outer diameter and borehole size. However, we can consider the thickness of the cement sheath separately and calculate stress values in the cement sheath using Equations (A11)-(A13) as shown in Figure 14. In this example, the cement thickness is ranging from $0.05 \mathrm{~m}$ to $0.18 \mathrm{~m}$. The thickness of the casing is $0.012 \mathrm{~m}$ and the outside diameter of the casing is $0.139 \mathrm{~m}$. The casing eccentricity is assumed to be $0.00 \mathrm{~m}, 0.01 \mathrm{~m}, 0.02 \mathrm{~m}$, $0.03 \mathrm{~m}, 0.04 \mathrm{~m}$. The crustal stress is $35 \mathrm{MPa}$ and wellbore pressure in the casing is $75 \mathrm{MPa}$. The other parameters are the same as Table 2.

Figure 14 shows that, when the casing is centered in the well, $\delta=0 \mathrm{~m}$, the equivalent stress remains constant with the increase of the thickness of the cement sheath. The casing eccentricity in wells causes high equivalent stress in the thin side of the cement sheath. In large e eccentricities, increasing of cement sheath thickness helps to decrease the equivalent stress, considerably. 


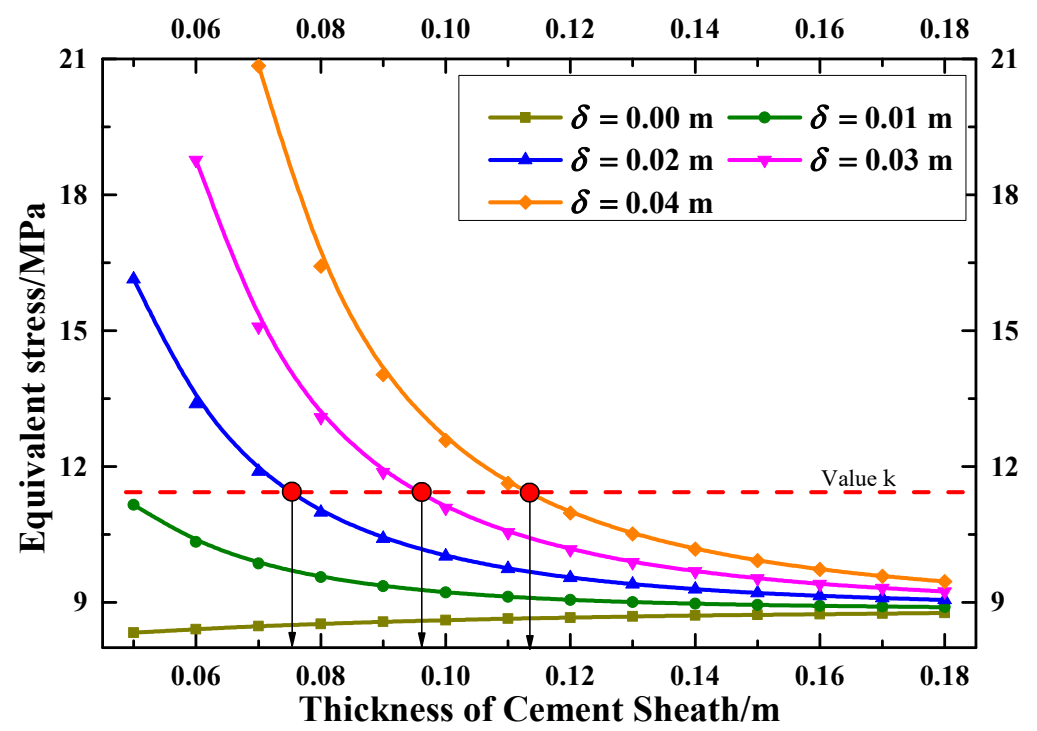

Figure 14. Variation of the equivalent stress of the cement sheath with the increase of cement thickness.

\subsection{Elastic Modulus of Cement Sheath}

The effects of the elastic modulus on the stress in cement sheath are calculated according to the Equations (A11)-(A13) and the results are shown in Figure 15, where the elastic modulus of cement is ranging from $10 \mathrm{GPa}$ to $40 \mathrm{GPa}$ [23]. The thickness of the casing is $0.012 \mathrm{~m}$ and the outside diameter of the casing is $0.139 \mathrm{~m}$. The thickness of the cement sheath is set as $0.065 \mathrm{~m}$. The eccentricity is as assumed to be $0.00 \mathrm{~m}, 0.01 \mathrm{~m}, 0.02 \mathrm{~m}, 0.03 \mathrm{~m}, 0.04 \mathrm{~m}$. The crustal stress is $35 \mathrm{MPa}$ and the fluid pressure in the casing is $75 \mathrm{MPa}$. From Figure 15, we can see that the effect of elastic modulus on equivalent stress in the cement is much smaller than the effect of the thickness of cement and casing, so using different cement grading is not recommended for this purpose.

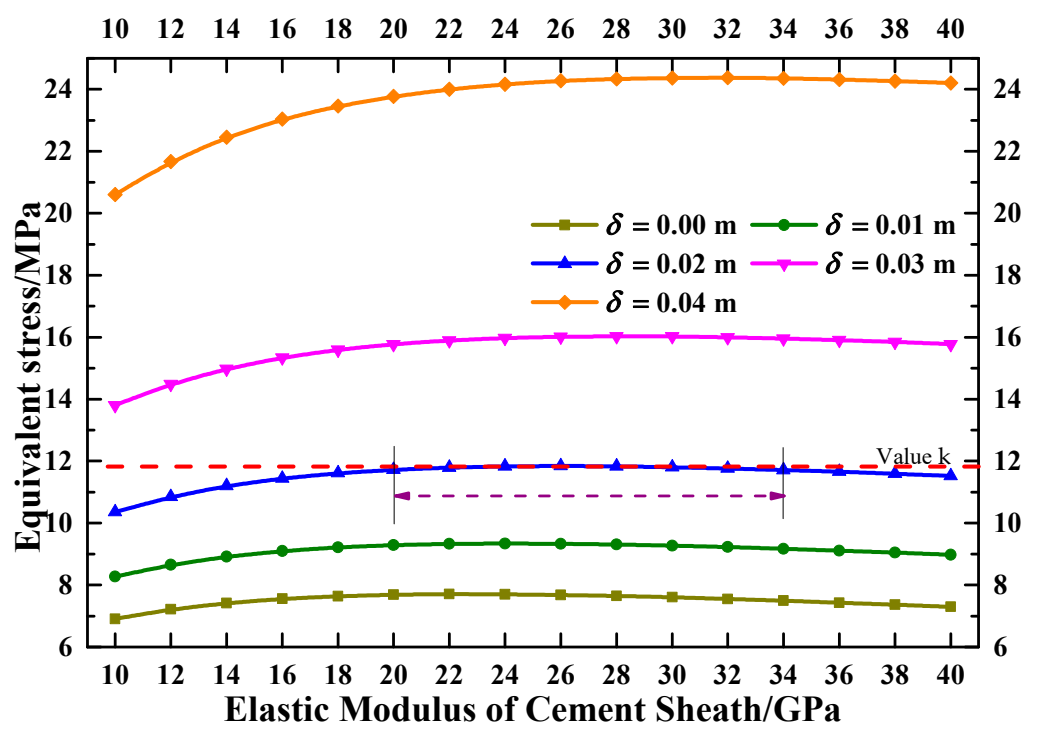

Figure 15. Variation of equivalent stress with the increase of cement elastic modulus.

\subsection{Case Study}

The change of stress in the cement sheath caused by casing eccentricity could be one of the reasons for serious well integrity problems in shale gas wells in Sichuan, China. Based on the reports, cement failure occurs in $54 \%$ wells in this field and five shale gas wells are chosen as cases to illustrate the use of the method proposed in this paper. The parameters of these five wells are shown in Table 3. 
The equivalent stresses on the inner interface at thinnest part of the cement sheath are calculated as shown in Figure 16. Meanwhile, the optimal parameters for casing-cement design are calculated for these wells.

Table 3. Initial and optimized parameters of casing and cement sheath in shale gas wells.

\begin{tabular}{|c|c|c|c|c|c|c|c|c|}
\hline & $\begin{array}{c}\text { Well } \\
\text { Number }\end{array}$ & $\begin{array}{l}\text { Casing } \\
\text { IR/mm }\end{array}$ & $\begin{array}{l}\text { Casing } \\
\mathrm{OR} / \mathrm{mm}\end{array}$ & $\begin{array}{c}\text { Thickness of } \\
\text { Cement } \\
\text { Sheath/mm }\end{array}$ & $\begin{array}{c}\text { Eccentricity/ } \\
\mathrm{mm}\end{array}$ & $\begin{array}{l}\text { Cement } \\
\text { EM/GPa }\end{array}$ & $\begin{array}{c}\text { Tectonic } \\
\text { Stress/MPa }\end{array}$ & $\begin{array}{c}\text { Pump } \\
\text { Pressure/MPa }\end{array}$ \\
\hline \multirow[b]{2}{*}{1} & In. Para. & 60.68 & 69.85 & 38.1 & 26 & 15 & 62 & 68 \\
\hline & Op. Para. & 58.68 & $\mathrm{~N} / \mathrm{A}$ & 50.8 & $\mathrm{~N} / \mathrm{A}$ & $\mathrm{N} / \mathrm{A}$ & $\mathrm{N} / \mathrm{A}$ & $\mathrm{N} / \mathrm{A}$ \\
\hline \multirow{2}{*}{2} & In. Para. & 57.80 & 69.85 & 38.1 & 17 & 15 & 69 & 74 \\
\hline & Op. Para. & 56.80 & $\mathrm{~N} / \mathrm{A}$ & 50.8 & $\mathrm{~N} / \mathrm{A}$ & $\mathrm{N} / \mathrm{A}$ & $\mathrm{N} / \mathrm{A}$ & $\mathrm{N} / \mathrm{A}$ \\
\hline \multirow[b]{2}{*}{3} & In. Para. & 51.36 & 63.50 & 20.65 & 8 & 13 & 70 & 80 \\
\hline & Op. Para. & $\mathrm{N} / \mathrm{A}$ & $\mathrm{N} / \mathrm{A}$ & 36.50 & $\mathrm{~N} / \mathrm{A}$ & $\mathrm{N} / \mathrm{A}$ & $\mathrm{N} / \mathrm{A}$ & $\mathrm{N} / \mathrm{A}$ \\
\hline \multirow{2}{*}{4} & In. Para. & 54.30 & 63.50 & 20.65 & 18 & 13 & 66 & 78 \\
\hline & Op. Para. & 50.30 & $\mathrm{~N} / \mathrm{A}$ & 36.50 & $\mathrm{~N} / \mathrm{A}$ & $\mathrm{N} / \mathrm{A}$ & $\mathrm{N} / \mathrm{A}$ & $\mathrm{N} / \mathrm{A}$ \\
\hline \multirow{2}{*}{5} & In. Para. & 48.59 & 57.15 & 19.05 & 12 & 13 & 40 & 76 \\
\hline & Op. Para. & 45.15 & $\mathrm{~N} / \mathrm{A}$ & 42.85 & $\mathrm{~N} / \mathrm{A}$ & $\mathrm{N} / \mathrm{A}$ & $\mathrm{N} / \mathrm{A}$ & $\mathrm{N} / \mathrm{A}$ \\
\hline
\end{tabular}

$\mathrm{N} / \mathrm{A}$ means that the parameters which have not been optimized; IR—inner radius; OR—outer radius; EM—elastic modulus; In. Para.-Initial parameters; Op. Para.—optimized parameters.

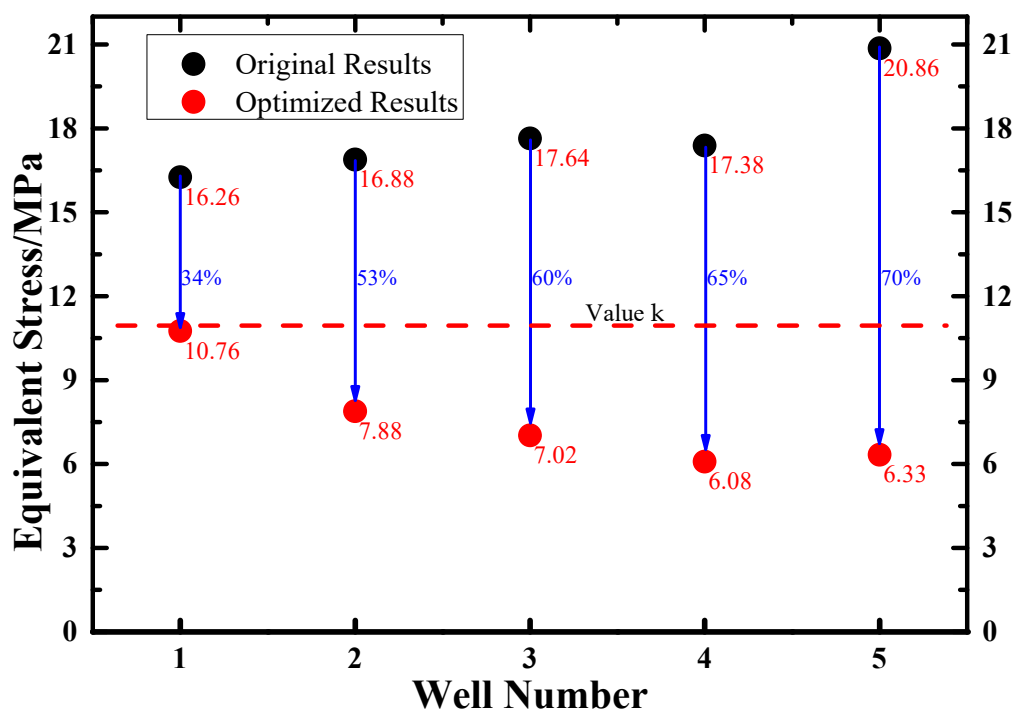

Figure 16. Equivalent stress of the cement sheath in original and optimized parameters.

According to the original parameters for the casing and cement sheath used in the field, the equivalent stress of the cement sheath in five wells is $16.26 \mathrm{MPa}, 16.88 \mathrm{MPa}, 17.64 \mathrm{MPa}, 17.38 \mathrm{MPa}$ and $20.86 \mathrm{MPa}$, respectively, which is much higher than permissible equivalent stress value, i.e., $\mathrm{k}$. The cement sheath integrity failures detected in these five wells in the field are consistent with the calculated results. Through a proper design of the casing and cement sheath, the stresses in these five wells can be lowered to values less than $\mathrm{k}$ with having the same casing eccentricity, to prevent the failure of the well integrity. However, in well Number 1, the equivalent stress with redesigned parameters is just smaller than $\mathrm{k}$. It is not safe for the integrity of cement sheath and other optimal design like increase the casing thickness can be considered. Well Number 5 has the largest equivalent stress in original parameters and its equivalent stress is decreased by $70 \%$ according to the revised design. Through the comparison of well Number 1 and well Number 5, we can see that the large casing eccentricity makes it hard to decrease the cement equivalent stress only based on adjusting geometrical parameters. As casing eccentricity can significantly increase the stress of the cement sheath and it cannot be completely avoided, some operational strategies need to be considered to decrease casing eccentricity. 


\section{Conclusions}

Casing sustained pressure (SCP) is a widespread problem in shale gas wells and, according to the analysis presented in this paper, we can see that casing eccentricity is one of the most important factors which affects the integrity of the cement sheath and causes SCP in shale gas wells. Based on the analysis, some conclusions are achieved.

(1) By employing the bipolar coordinate system, a method for calculating stress in the cement sheath I proposed that considers casing eccentricity. The analytical model is verified by FEA.

(2) The casing eccentricity will dramatically increase stress in the cement sheath and expedite cement sheath failure. It is important to decrease the risk of cement failure by improving casing centralization, and increasing casing thickness.

The analytical method for calculating stress in an eccentric cement sheath is done based on the assumption that the tectonic stresses are uniform. Further work should be focused on stress anisotropy.

Author Contributions: All the authors conceived and designed the study. K.L. performed the formula derivation, model calculation and wrote the paper; D.G. and A.D.T. discussed the approach and edited the manuscript.

Funding: This research was funded by the Natural Science Foundation of China (Grant numbers: U1762214 and 51521063) and this research is also supported by other projects (Grant numbers: 2017ZX05009-003, 2016YFC0303303, 2017ZX05005-005-007, 2018YFB0605502).

Acknowledgments: The first author gratefully acknowledges the support from Energy and Mineral Engineering Department at Pennsylvania State University. The first author also acknowledges the support from the China Scholarship Council (No. 201706440071).

Conflicts of Interest: The authors declare that there is no conflict of interests regarding the publication of this paper.

\section{Nomenclature}

$\begin{array}{ll}P_{\mathrm{i}} & \text { Fluid pressure in casing } \\ \sigma_{\mathrm{O}} & \text { Crustal stress } \\ S_{1}, S_{2} & \text { Radial stress on first interface and second interface with no casing eccentricity } \\ S_{1}^{\prime}, S_{2}^{\prime} & \text { Radial stress on first interface and second interface with casing eccentricity } \\ \lambda & \text { positive real number } \\ \alpha, \beta & \text { Coordinate axes of the bipolar coordinate system } \\ R & \text { Radius of this circle in cement sheath } \\ h_{\varphi} & \text { Thickness of the cement sheath at any section } \\ \zeta & \text { Bipolar coordinate variable } \\ \xi, \eta & \text { Bipolar coordinate component } \\ r_{1} & \text { Radius of circle } \alpha_{1} \\ r_{2} & \text { Radius of circle } \alpha_{2} \\ \overrightarrow{\alpha \alpha} & \text { Radial stress in cement sheath } \\ \overrightarrow{\beta \beta} & \text { Circumferential stress in cement sheath } \\ \overrightarrow{\alpha \beta} & \text { Shear stress in cement sheath } \\ \mathrm{k} & \text { Shear yield strength of cement sheath }\end{array}$

\section{Appendix}

In a bipolar coordinate system, we take the curvilinear co-ordinate shown by conjugate function:

$$
z=i \lambda \operatorname{coth} \frac{\zeta}{2}=\frac{\lambda \sin \alpha}{\cosh \alpha-\cos \beta} \beta-i \frac{\lambda \sinh \beta}{\cosh \alpha-\cos \beta}
$$


The $\alpha$ and $\beta$ are coordinate axes of the bipolar coordinate system. As $z=x+i y$, we know that in the Cartesian coordinate system:

$$
\left\{\begin{array}{l}
x=\lambda \cdot \sin \beta /(\cosh \alpha-\cos \beta) \\
y=\lambda \cdot \sinh \alpha /(\cosh \alpha-\cos \beta)
\end{array}\right.
$$

The arc along the cement inner and outer interface, $\alpha$ and $\beta$, are constant, respectively, so we can get the constant coefficients $h$ as

$$
h=\frac{\cosh \alpha-\cos \beta}{\alpha}
$$

From Equation (A1) we know that the expression of $\zeta$ can be shown as

$$
\zeta=\frac{z+i \lambda}{z-i \lambda}=\xi+i \eta=\ln \frac{r_{1}}{r_{2}}+i\left(\theta_{1}-\theta_{2}\right)
$$

As we can see, the $\xi=\ln \frac{r_{1}}{r_{2}}$ and $\eta=\theta_{1}-\theta_{2}$, where $z$ is the rectangular coordinate variable, $x$ and $y$ are coordinate components, respectively; $\zeta$ is the bipolar coordinate variables, $\xi$ and $\eta$ are bipolar coordinate components, respectively; $\lambda$ is a constant. Equation (A2) can be simplified by eliminate the $\beta$. We then obtain

$$
x^{2}+(y-\lambda \operatorname{coth} \alpha)^{2}=\lambda^{2} \operatorname{csch}^{2} \alpha
$$

Equation (A5) illustrates a circle with radius of $\lambda \operatorname{csch} \alpha$. Incidentally, its center is on the $y$ axis and $\lambda \operatorname{coth} \alpha$ distance from the origin of coordinate system. When $\alpha=\alpha_{1}$, the radius of the circle is $\lambda \operatorname{csch} \alpha_{1}$, the center of the circle is on the $y$ axis and its distance from the origin of coordinate system is $\lambda \operatorname{coth} \alpha_{1}$. When $\alpha=\alpha_{2}$, the radius of the circle is $\lambda \operatorname{csch} \alpha_{2}$, the center of the circle is on the $y$ axis and its distance from the origin of coordinate system is $\lambda \operatorname{coth} \alpha_{2}$. If the inner interface of the cement is treated as a circle named Circle 1 and the outer interface of cement is treated as a circle named Circle 2, it can be seen from Figure 4 that the center of Circle 1 and Circle 2 are different. It will be more convenient to introduce the bipolar coordinate to analyze the stress of cement. At this time, $\alpha=\alpha_{1}$ indicates the inner interface of cement Circle 1 and $\alpha=\alpha_{2}$ indicates the outer interface of cement Circle 2. From the known radius $r_{1}, r_{2}$ and distance between the centers of the outer and inner interface of the cement sheath, the constant $\lambda, \alpha_{1}$ and $\alpha_{2}$ can be determined as

$$
\left\{\begin{array}{l}
\lambda=\frac{1}{2 \delta} \cdot \sqrt{r_{1}^{4}+r_{2}^{4}-2 r_{1}^{2} r_{2}^{2}-2 \delta^{2} r_{1}^{2}-2 \delta^{2} r_{2}^{2}+\delta^{4}} \\
\alpha_{1}=\operatorname{arcsinh}\left(\frac{\lambda}{r_{1}}\right) \\
\alpha_{2}=\operatorname{arcsinh}\left(\frac{\lambda}{r_{2}}\right)
\end{array}\right.
$$

Due to the body force not being considered, the stress function for calculating stress in cement satisfies $\nabla^{4} \chi=0$.

The load on the outer interface of cement is $S_{2}=\sigma_{2}$ and on the inner interface of cement is $S_{1}=\sigma_{1}$. According to the equations derived by Jeffery, the form of stress function can be assumed as Equation (A7).

$$
h \chi=\mathrm{B}_{0} \alpha(\cosh \alpha-\cos \beta)+\left(\mathrm{A}_{1} \cosh 2 \alpha+\mathrm{B}_{1}+\mathrm{C}_{1} \sinh 2 \alpha\right) \cos \beta
$$

By substituting boundary conditions to Equation (A7), the undetermined constant $B_{0}, A_{1}, B_{1}, C_{1}$ can be determined, as shown from Equation (A7a) to Equation (A7d).

$$
\begin{aligned}
& \mathrm{B}_{0}=2 \alpha \mathrm{N}\left(S_{1}-S_{2}\right) \cosh \left(\alpha_{1}-\alpha_{2}\right) \\
& \mathrm{A}_{1}=-\alpha \mathrm{N}\left(S_{1}-S_{2}\right) \sinh \left(\alpha_{1}+\alpha_{2}\right)
\end{aligned}
$$




$$
\begin{gathered}
\mathrm{C}_{1}=\alpha \mathrm{N}\left(\mathrm{S}_{1}-\mathrm{S}_{2}\right) \cosh \left(\alpha_{1}+\alpha_{2}\right) \\
\mathrm{B}_{1}=\alpha \mathrm{N}\left[\mathrm{S}_{1} \cosh \left(\alpha_{1}-\alpha_{2}\right) \sinh 2 \alpha_{2}-\mathrm{S}_{2} \cosh \left(\alpha_{1}-\alpha_{2}\right) \sinh 2 \alpha_{1}+\left(\mathrm{S}_{1}+\mathrm{S}_{2}\right) \sinh \left(\alpha_{1}-\alpha_{2}\right)\right]
\end{gathered}
$$

where $\mathrm{N}=0.5 \operatorname{csch}\left(\alpha_{1}-\alpha_{2}\right)\left[\sinh ^{2} \alpha_{1}+\sinh ^{2} \alpha_{2}\right]^{-1}$.

The expression of stress function is now achieved and the stress in the cement can be calculated according to Equation (A8).

$$
\left\{\begin{array}{l}
\lambda \overrightarrow{\alpha \alpha}=\left[(\cosh \alpha-\cos \beta) \frac{\partial^{2}}{\partial \beta^{2}}-\sinh \alpha \frac{\partial}{\partial \alpha}-\sin \beta \frac{\partial}{\partial \beta}+\cosh \alpha\right](h \chi) \\
\lambda \overrightarrow{\beta \beta}=\left[(\cosh \alpha-\cos \beta) \frac{\partial^{2}}{\partial \alpha^{2}}-\sinh \alpha \frac{\partial}{\partial \alpha}-\sin \beta \frac{\partial}{\partial \beta}+\cosh \beta\right](h \chi) \\
\lambda \overrightarrow{\alpha \beta}=-(\cosh \alpha-\cos \beta) \frac{\partial^{2}(h \chi)}{\partial \alpha \partial \beta}
\end{array}\right.
$$

The expression of $h \chi$ in Equation (A4) is substituted into Equation (A5) to get the circumstance stress, radial stress and shear stress of the cement at any position in cement. In Jeffery's research, the circumstance stress on the outer and inner interface is solved. The circumstance stress on the cement interface is shown as follows.

On the inner interface of cement, $\alpha=\alpha_{1}$, the circumstance can be calculated as

$$
\overrightarrow{\beta \beta}=-S_{1}+4\left(S_{1}-S_{2}\right) \mathrm{N}\left(\cosh \alpha_{1}-\cos \beta\right)\left[\sinh \left(\alpha_{1}-\alpha_{2}\right) \cos \beta+\sinh \alpha_{1} \cosh \left(\alpha_{1}-\alpha_{2}\right)\right]
$$

On the outer interface of cement, $\alpha=\alpha_{2}$, the circumstance can be calculated as

$$
\overrightarrow{\beta \beta}=-S_{2}-4\left(S_{1}-S_{2}\right) \mathrm{N}\left(\cosh \alpha_{2}-\cos \beta\right)\left[\sinh \left(\alpha_{1}-\alpha_{2}\right) \cos \beta-\sinh \alpha_{2} \cosh \left(\alpha_{1}-\alpha_{2}\right)\right]
$$

The method for calculating the stress at any point in the cement is achieved in this paper. The method for calculating circumstance stress is shown in Equation (A11). The method for calculating radial stress is shown in Equation (A12). The method for calculating shear stress is shown in Equation (A13).

$$
\begin{aligned}
& \overrightarrow{\beta \beta}=\sin ^{2} \beta \cdot \mathrm{N} \cdot\left[-\left(S_{1}-S_{2}\right) \sinh \left(\alpha_{1}-\alpha_{2}\right)+S_{1} \sinh \left(2 \alpha_{2}\right) \sinh \left(\alpha_{1}-\alpha_{2}\right)+S_{2} \sinh \left(2 \alpha_{1}\right) \cosh \left(\alpha_{1}-\alpha_{2}\right)-\right. \\
& \overrightarrow{\alpha \beta}=-2 \mathrm{~N}(\cos \beta-\cosh \alpha)\left(S_{1}-S_{2}\right)\left[\sin \beta \cosh 2 \alpha \cosh \left(\alpha_{1}+\alpha_{2}\right)-\sinh 2 \alpha \sinh \left(\alpha_{1}+\alpha_{2}\right)\right. \\
& -\sinh 2 \beta \cosh \left(\alpha_{1}-\alpha_{2}\right) \text { ] }
\end{aligned}
$$




\section{References}

1. Thiercelin, M.J.; Dargaud, B.; Baret, J.F.; Rodriguez, W.J. Cement design based on cement mechanical response. Soc. Pet. Eng. 1998, 13, 266-273.

2. Dusseault, M.B.; Gray, M.N.; Nawrocki, P.A. Why oilwells leak: Cement behavior and long-term consequences. In Proceedings of the International Oil and Gas Conference and Exhibition in China, Beijing, China, 7-10 November 2000.

3. Zhu, H.Y.; Deng, J.G.; Zhao, J.; Zhao, H.; Liu, H.L.; Wang, T. Cementing failure of the casing-cement-rock interfaces during hydraulic fracturing. Comput. Concr. 2014, 14, 91-107. [CrossRef]

4. Taleghani, A.D.; Klimenko, D. An analytical solution for microannulus cracks developed around a wellbore. J. Energy Resour. Technol. 2015, 137. [CrossRef]

5. Wang, W.; Taleghani, A.D. Impact of hydraulic fracturing on cement sheath integrity: A modeling approach. J. Nat. Gas Sci. Eng. 2017, 44, 265-277. [CrossRef]

6. Chu, W.; Shen, J.; Yang, Y.; Li, Y.; Gao, D.L. Calculation of micro-annulus size in casing-cement sheath-formation system under continuous internal casing pressure change. Pet. Explor. Dev. 2015, 42, 414-421. [CrossRef]

7. Goodwin, K.J.; Crook, R.J. Cement sheath stress failure. SPE Drill. Eng. 1992, 7, 291-296. [CrossRef]

8. Fang, J.; Gu, Y.H.; Mi, F.Z. A numerical analysis of casing collapse under non-uniform load. China Pet. Mach. 1999, 27, 34-37.

9. Wang, W.; Taleghani, A.D. Three-dimensional analysis of cement sheath integrity around Wellbores. J. Pet. Sci. Eng. 2014, 121, 38-51. [CrossRef]

10. Wang, Y.B.; Gao, D.L.; Fang, J. Mechanical characteristics analysis of casing-cement ring-formation multilayer composite system. Chin. J. Appl. Mech. 2014, 31, 387-392.

11. Fan, M.; Li, J.; Liu, G. New method to analyse the cement sheath integrity during the volume fracturing of shale gas. Energies 2018, 11, 750. [CrossRef]

12. Kim, J.; Moridis, G.J.; Martinez, E.R. Investigation of possible wellbore cement failures during hydraulic fracturing operations. J. Pet. Sci. Eng. 2016, 139, 254-263. [CrossRef]

13. De Andrade, J.; Sangesland, S. Cement sheath failure mechanisms: Numerical estimates to design for long-term well integrity. J. Pet. Sci. Eng. 2016, 147, 682-698. [CrossRef]

14. De Andrade, J.; Torsæter, M.; Todorovic, J.; Opedal, N.; Stroisz, A.; Vralstad, T. Influence of casing centralization on cement sheath integrity during thermal cycling. In Proceedings of the IADC/SPE Drilling Conference and Exhibition, Fort Worth, TX, USA, 4-6 March 2014.

15. Tao, Q.; Chen, X. Causal analysis and countermeasures on B sustained casing pressure of shale-gas horizontal wells in the Sichuan Basin. Oil Drill. Prod. Technol. 2017, 39, 588-593.

16. Wu, J.L. Elastic Mechanics, 2nd ed.; Higher Education Press: Beijing, China, 2011.

17. Liu, K.; Wang, Y.B.; Gao, D.L.; Li, X.Y.; Zhang, Y. Effects of hydraulic fracturing on horizontal wellbore for shale gas. Acta Petrolei Sinica 2016, 37, 406-414.

18. Liu, K.; Gao, D.L.; Taleghani, A.D. Analysis on integrity of cement sheath in the vertical section of wells during hydraulic fracturing. J. Pet. Sci. Eng. 2018, 168, 370-379. [CrossRef]

19. Timoshenko, S.; Goodier, J.N. Theory of Elasticity, 2nd ed.; Mcgraw Hill: New York, NY, USA, 1951.

20. Jeffery, G.B. IX. Plane stress and plane strain in bipolar co-ordinates. Philos. Trans. R. Soc. Lond. A 1921, 221, 265-293. [CrossRef]

21. Liu, K.; Gao, D.L.; Zeng, J.; Fang, J.; Wang, Y.B. Annulus pressure analysis of a shale gas well under varied temperatures and pressures. Pet. Drill. Technol. 2017, 45, 8-14.

22. Liu, K.; Gao, D.L.; Wang, Y.B.; Yang, Y.C. Effect of local loads on shale gas well integrity during hydraulic fracturing process. J. Nat. Gas Sci. Eng. 2017, 37, 291-302. [CrossRef]

23. Jun, L.; Mian, C.; Gonghui, L.; Hui, Z. Elastic-plastic analysis of casing-concrete sheath-rock combination. Acta Petrolei Sinica 2005, 26, 99-103.

(C) 2018 by the authors. Licensee MDPI, Basel, Switzerland. This article is an open access article distributed under the terms and conditions of the Creative Commons Attribution (CC BY) license (http:/ / creativecommons.org/licenses/by/4.0/). 